\title{
DISTRIBUIÇÃO E FORMAS DE OCORRÊNCIA DE ZINCO EM SOLOS NO MUNICÍPIO DE VAZANTE - $\mathrm{MG}^{(1)}$
}

\author{
Meubles Borges Júnior ${ }^{(2)}$, Jaime Wilson Vargas de Mello ${ }^{(3)}$, Carlos Ernesto \\ G.R. Schaefer ${ }^{(4)}$, Tânia Mara Dussin ${ }^{(5)} \&$ Jorge Amim Júnior ${ }^{(6)}$
}

\begin{abstract}
RESUMO
A contaminação de solos é um problema atual que requer investigação detalhada no sentido de estabelecer critérios para a distinção entre anomalias naturais e contribuição antrópica. $O$ trabalho foi desenvolvido com o objetivo de avaliar a distribuição e as formas de ocorrência de Zn para identificar a origem de valores anômalos em solos adjacentes a áreas de mineração no município de Vazante-MG. Foram coletadas amostras de perfis de solos em remanescentes sobre a área minerada e em posições a jusante e a montante desta, nas camadas de 0-2, 2$5,5-10,10-20,20-50,50-100$, e 100-150 cm. Um estudo de extração seqüencial avaliou os teores de $\mathrm{Zn}$ nas formas: (a) solúvel; (b) trocável; (c) associada a carbonatos; (d) associada a óxidos amorfos; (e) associada a óxidos cristalinos; (f) associada à matéria orgânica; (g) residual; e (h) total. Verificou-se que os teores de Zn, de modo geral, são mais elevados nas áreas localizadas sobre a zona de mineralização, com solos mais jovens (Cambissolos e Neossolos), em relação aos solos mais intemperizados (Latossolos e Argissolos), localizados tanto a montante quanto a jusante da área minerada. Os teores totais foram muito altos. Mesmo considerando apenas as formas solúvel e trocável, mais lábeis, em alguns perfis os valores foram superiores aos teores totais encontrados naturalmente em solos. Verificou-se um padrão decrescente dos teores com a profundidade nos perfis localizados fora da área minerada. Por outro lado, os teores de $\mathrm{Zn}$ aumentaram com a profundidade em um Cambissolo localizado na área minerada. Não houve diferença significativa entre os teores de Zn das áreas a montante e a jusante em
\end{abstract}

\footnotetext{
(1) Parte da Tese de Doutorado do primeiro autor apresentada ao Programa de Pós-graduação de Solos e Nutrição de Plantas da Universidade Federal de Viçosa - UFV. Recebido para publicação em maio de 2007 e aprovado em junho de 2008.

(2) Professor do Centro Universitário de Caratinga - CUC. Av. Moacyr de Mattos 49, CEP 35300-047 Caratinga (MG). E-mail: meubles@funec.br

(3) Professor Associado do Departamento de Solos, Universidade Federal de Viçosa - UFV. Av. PH Rolfs s/n, CEP 36570-000 Viçosa (MG). Pesquisador CNPq. E-mail: jwvmello@ufv.br

(4) Professor Associado do Departamento de Solos, UFV. Pesquisador CNPq. E-mail: carlos.schaefer@ufv.br;

(5) Professor Associado do Departamento de Geologia do Instituto de Geociências da Universidade Federal de Minas Gerais - DG/ IGC/UFMG. Caixa Postal 2608, CEP 31270-901 Belo Horizonte (MG). E-mail: tdussin@gmail.com

(6) Estudante de Mestrado no Programa de Agroquímica, UFV.
} 
todas as formas químicas avaliadas, sugerindo que não se pode presumir efeito antrópico na dispersão do Zn em áreas adjacentes à zona de mineralização.

Termos de indexação: solos contaminados, mineração, extração seqüencial, distribuição de $\mathrm{Zn}$.

\title{
SUMMARY: DISTRIBUTION AND FORMS OF ZINC IN SOILS FROM VAZANTE, STATE OF MINAS GERAIS (BRASIL)
}

\begin{abstract}
Soil contamination is nowadays a problem that requires detailed investigation in order to set up criteria for distinction between natural anomalies and antropogenic contribution. This work was carried out to evaluate zinc distribution and fractions, aiming to identify the origin of high $\mathrm{Zn}$ content in soils around mining areas in the Vazante county -MG (Brazil). Soil profiles were sampled in mined areas, and in upslope and downslope positions at depths of $0-2,2-5,5-10,10-20,20-50,50-100$ and $100-150 \mathrm{~cm}$. A sequential extraction method was employed to evaluate zinc concentrations in the following fractions: (a) soluble; (b) exchangeable; (c) carbonate-associated; (d) associated with amorphous oxides; (e) associated with crystalline oxides; (f) organically bound; (g) residual and (h) total. In general, Zn levels were higher in the younger soils (Inceptisols) of the mined than in highly weathered soils (Oxisols and Ultisols) both up and downslope from the mine. Total zinc levels were extremely high. Even when only the soluble and exchangeable $\mathrm{Zn}$ forms are considered, the values in some profiles are higher than those reported for naturally occurring total soil contents. A decreasing trend in the contents with soil depth was verified outside the mineralized area (in both up and downslope positions). On the other hand, the $\mathrm{Zn}$ contents increased with depth in the Cambisol within the mined area. There was no significant difference between mean $\mathrm{Zn}$ contents in upslope and downslope soils for all extracted $\mathrm{Zn}$ fractions. Anthropogenic contribution to the high $\mathrm{Zn}$ content in soils in areas surrounding the mined zone is therefore not supported.
\end{abstract}

Index terms: soil contamination, mining, sequential extraction, Zn distribution.

\section{INTRODUÇÃO}

A região de Vazante-MG é de grande interesse socioeconômico e ambiental, já que se trata de área com elevados teores de Zn. A impossibilidade de diferenciar anomalias geogênicas daquelas advindas de processos de contaminação relacionados à ação antrópica sugere estudos sobre a distribuição e formas de Zn nos solos a fim de contribuir para melhor avaliação das possíveis causas de valores anômalos em solos e água da região.

A mineralização em Vazante é composta principalmente de willemita $\left(\mathrm{Zn}_{4}\left(\mathrm{Si}_{2} \mathrm{O}_{7}\right)\right)$ e calamina (também denominado hemimorfita, $\left.\mathrm{Zn}_{4}\left(\mathrm{Si}_{2} \mathrm{O}_{7}\right)(\mathrm{OH}) \cdot 2 \mathrm{H}_{2} \mathrm{O}\right)$ e está associada a rochas carbonáticas da Formação Vazante, com corpos de minério formados por veios associados a uma falha longitudinal de direção NE. Segundo Rigobello et al. (1988), a Formação Vazante é restrita à seqüência predominantemente dolomítica. Neste trabalho, será considerado o termo "mineralização" para se referir a depósitos de minérios e "mineração" para indicar a exploração desses minérios.

Os depósitos de Zn têm início a $2 \mathrm{~km}$ a $\mathrm{NE}$ de Vazante até cerca de $8 \mathrm{~km}$ na direção NE. Dividido em dois segmentos principais, o sul aflorante e o norte sem ocorrência em superfície, o minério willemítico apresenta mineralogia simples, ocorrendo willemita com hematita associada. Já o minério calamínico localiza-se sempre a leste e junto ou próximo do corpo willemítico. Ocorre principalmente sob a forma de brecha de colapso em folhelhos e dolomitos enriquecidos em Zn (Rigobello et al., 1988).

Os metais pesados em solos podem estar associados a diversas formas químicas. Em solos não poluídos, esses metais estão contidos principalmente nos minerais primários ou ligados a óxidos, formando espécies relativamente imóveis. Por outro lado, em solos contaminados por ação antrópica recente, presume-se que esses metais devam se apresentar em formas mais móveis. Portanto, estudos de biodisponibilidade de metais no solo são imprescindíveis para qualquer trabalho com o objetivo de avaliar casos de contaminação por esses elementos. Porém, não existe um extrator-padrão que desempenhe com exatidão essa função (Ribeiro-Filho et al., 2001).

Segundo Amaral Sobrinho (1997), a contaminação por metais pesados tem sido avaliada por meio de extrações químicas simples e seqüenciais, que identificam as formas químicas em que esses elementos se encontram ou predominam associados. A extração seqüencial em solos pode ser definida como a extração e a quantificação de frações do solo que são 
denominadas, funcionalmente como o conteúdo disponível para a planta. Contudo, na prática, a fração do solo pode ser indefinida e o extrator pode não ser específico para a forma química considerada.

O problema de seletividade incompleta dos extratores usados em análise seqüencial consiste no ataque adicional a outras frações e também na ineficiência em deslocar completamente a fração para a qual foram destinados. Não obstante, os métodos de extração seqüencial permitem obter informações sobre os tipos de associação dos metais no solo, além de permitir que se façam inferências sobre a biodisponibilidade (Ribeiro-Filho et al., 2001).

Vários métodos de extração seqüencial têm sido adotados e adaptados para diferentes matrizes em estudos ambientais, gerando um expressivo número de publicações sobre o assunto (Guevara-Riba et al., 2004; Canepari et al., 2005; Pazos-Capeáns et al., 2005; Basílio et al., 2005). Em estudo de disponibilidade de Zn em Argissolos arenosos, André et al. (2003) adaptaram um procedimento de extração em função das características do solo em estudo, considerando as seguintes frações: trocável (Shuman, 1985), ligado a óxidos de Mn (Chao, 1972), ligado à matéria orgânica (Miller et al., 1986), ligado aos óxidos de Fe (Shuman, 1985), e residual (Camargo et al., 1986). Pereira et al. (2007), estudando a distribuição e mobilidade de elementos-traço em sedimentos superficiais, utilizaram um sistema de extração seqüencial em três etapas, conforme sugerido pelo "Community Bureau of Reference", atualmente "Standards, Measurements and Testing Programme", desenvolvido com o objetivo de padronizar os diferentes procedimentos descritos na literatura. Tal procedimento considera as seguintes fracões: solúvel (ácido acético 0,11 $\mathrm{mol} \mathrm{L}^{-1}$ ), redutível (cloridrato de hidroxilamina, $0,5 \mathrm{~mol} \mathrm{~L}^{-1}$ ), oxidável (peróxido de hidrogênio $8,8 \mathrm{~mol} \mathrm{~L}^{-1}$ seguido de acetato de amônio $1,0 \mathrm{~mol} \mathrm{~L}^{-1}$ ) e residual (água régia).

O esquema de extração seqüencial mais usado foi originalmente proposto por Tessier et al. (1979), o qual tem sido modificado por vários autores (Rauret, 1998). Muitas dessas modificações dizem respeito mais especificamente à extração das frações associadas aos óxidos e hidróxidos de Fe e Mn. Chlopecka et al. (1996) relatam que, embora existam limitações nos métodos para determinar a biodisponibilidade dos metais, a seqüência extratora de Tessier et al. (1979) é uma abordagem analítica adequada para se inferir o comportamento dos metais pesados no solo.

As técnicas de extração seqüencial usadas em estudos de contaminação por metais em solos e sedimentos objetivam, principalmente, avaliar a disponibilidade potencial, a mobilidade e, em alguns casos, sua migração em perfis de solos, comumente associada a problemas de contaminação do lençol freático (Gleyzes et al., 2002).

Em vista do exposto, este trabalho visa contribuir na investigação de efeitos antrópicos em áreas contaminadas. Para isso, é examinada a distribuição das diferentes formas de Zn ao longo de perfis de solos sobre uma anomalia geológica e em posições a montante e a jusante desta. Neste caso, a interpretação dos resultados segue a abordagem estatística convencional de comparações por contrastes ortogonais para avaliação da dispersão da anomalia em áreas adjacentes. O objetivo foi avaliar a distribuição das diferentes formas de Zn em perfis de solos localizados em área anômala, bem como contribuir para investigar se a origem da contaminação é natural ou se há efeito antrópico recente na dispersão do Zn em áreas adjacentes.

\section{MATERIAL E MÉTODOS}

As amostras de solo foram coletadas em remanescentes sobre a área mineralizada e a jusante e a montante desta. Os locais de coleta foram selecionados a partir de análise conjunta de mapas geológicos, geomorfológicos, hidrológicos em diferentes classes de solo que ocorrem na área. Foram consideradas áreas a montante, aquelas que, devido a sua localização, provavelmente não são atingidas pelas atividades da mina. Por outro lado, as áreas a jusante são aquelas que, em função da sua localização, podem sofrer alteração (ex: contaminação por drenagem ou poeira). Todas as amostras coletadas foram georreferenciadas (Figura 1) em perfis de solos assim caracterizados:

\section{Perfil 1 - Neossolo Litólico}

Localizado em área não minerada; perfil situado no terço médio de encosta sobre depósito de sopé na parte inferior da faixa mineralizada de willemitacalamina. A vegetação local é aberta e compõe-se de abundantes gramíneas e calamináceas, com tipologia de campo-rupestre. O perfil apresentava, ainda, bolsões de material pedogenizado até $150 \mathrm{~cm}$ de profundidade. A estrutura do horizonte A é forte, média, e pequena granular, cascalhenta. Transição ondulada entre os horizontes A e Cr.

\section{Perfil 2 - Cambissolo Háplico}

Localizado em área não minerada; perfil situado no terço médio/superior de encosta sobre a faixa mineralizada de calamina, com vegetação graminosa rica em capim-colchão (Digitaria spp.) e calamináceas. Blocos e afloramentos de calamina dispersos, formando uma couraça laterítica. A área é dominada por Cambissolo, com horizonte A moderado ou A proeminente.

\section{Perfil 3 - Cambissolo Háplico}

Localizado em área não minerada; perfil situado no terço inferior de encosta com mineralização de willemita formando patamar aplainado (terracete) com vegetação de gramíneas, ciperáceas e calamináceas (tipologia de campo rupestre, com extrato arbóreo ausente). 


\section{Perfil 4 - Cambissolo Húmico}

Localizado na área minerada, supostamente sobre corpo mineralizado com calamina. Apresenta vegetação de tipo Cerrado, com calamináceas e abundantes crostas biológicas. Situa-se no topo da paisagem, com área supostamente mineralizada em nível mais baixo. Do ponto amostrado, avista-se alinhamento do corpo mineralizado, seguindo em direção da escarpa.

\section{Perfil 5 - Cambissolo Húmico/Litólico Húmico}

Localizado na área minerada, em posição semelhante ao perfil 4, porém em cota menos elevada sobre área de ocorrência da calamina.

\section{Perfil 6 - Latossolo Vermelho eutrófico argissólico}

Localizado a jusante da área mineralizada. A presença de material latossólico abaixo de $75 \mathrm{~cm}$ de profundidade é discordante da parte superior com B textural.

\section{Perfil 7 - Neossolo Flúvico}

Localizado a jusante da mina, em área não mineralizada, na planície de inundação do rio Santa Catarina. Observou-se a presença de raízes finas em todo o perfil. Registrou-se na área palmeiras de babaçu e goiabeiras em abundância.

\section{Perfil 8 - Latossolo Vermelho}

Localizado a jusante da mina em área não mineralizada. Observou-se a presença de raízes em todo o perfil. Área com vegetação de mata.

\section{Perfil 9 - Argissolo Vermelho}

Localizado em área não mineralizada, a montante da mina, sob vegetação de floresta secundária e pastagem de capim-colonião.

\section{Perfil 10 - Latossolo Vermelho}

Localizado em área fora do alinhamento do corpo mineralizado a montante da mina. Observou-se presença de raízes finas e médias e finas em todo o perfil. A área apresenta vegetação de cerrado e pastagem.

\section{Perfil 11 - Cambissolo}

Localizado em área não mineralizada, a montante da mina, porém próximo da mina em posição semelhante à do perfil 5 . Presença de fragmentos de dolomita e quartzo substituindo a dolomita. Perfil bem drenado e raízes abundantes em todo o perfil. Área sob mata situada no terço médio de elevação ao longo da escarpa em área dolomítica. Apresenta um horizonte A enterrado na profundidade de 18 a $25 \mathrm{~cm}$.

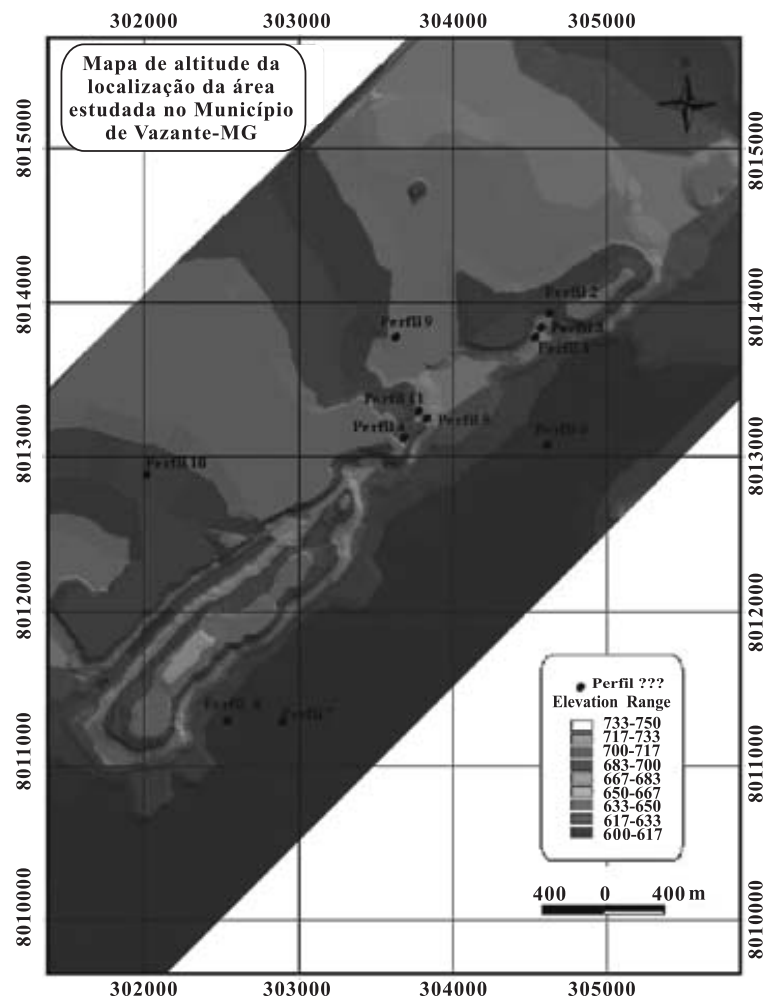

Figura 1. Localização dos perfis coletados com referência de altitude.

As amostras de cada perfil foram coletadas em várias camadas (0 a $2 \mathrm{~cm} ; 2$ a $5 \mathrm{~cm} ; 5$ a $10 \mathrm{~cm} ; 10$ a $20 \mathrm{~cm} ; 20$ a $50 \mathrm{~cm}$; 50 a 100 e 100 a $150 \mathrm{~cm})$, com exceção do perfil 4 que não foi amostrado abaixo dos $100 \mathrm{~cm}$. Após as coletas, as amostras foram secas ao ar, destorroadas e tamisadas em peneiras de $2,0 \mathrm{~mm}$ de abertura de malha, procedendo-se a análises físicoquímicas de rotina e fracionamento do $\mathrm{Zn}$.

As análises de caracterização físico-química constaram de: $\mathrm{pH}\left(\mathrm{em} \mathrm{H}_{2} \mathrm{O}\right.$ e $\left.\mathrm{KCl}\right) ; \mathrm{Ca}^{2+}, \mathrm{Mg}^{2+}, \mathrm{K}^{+}$, $\mathrm{Na}^{+}$e $\mathrm{Al}^{3+}$; acidez potencial em $\mathrm{pH} 7(\mathrm{H}+\mathrm{Al}) ; \mathrm{P}$; matéria orgânica e textura dos solos, de acordo com Embrapa $(1979,1999)$. Os dados da mineralogia da área foram obtidos da dissertação de mestrado de Monteiro (1997).

Para a determinação do teor total de $\mathrm{Zn}$ foram utilizados $0,5 \mathrm{~g}$ de solo, triturado em almofariz de ágata, e uma mistura de $\mathrm{HNO}_{3}(8 \mathrm{~mL}), \mathrm{HCl}(5 \mathrm{~mL})$ e HF $(5 \mathrm{~mL})$ com digestão em microondas modelo ETHOS PLUS, Labstation - Milestone. A digestão foi programada de forma a atingir $160^{\circ} \mathrm{C} \mathrm{em} 6 \mathrm{~min}$, mais 4 min para atingir $210^{\circ} \mathrm{C}$, permanecendo por 20 min nesta temperatura. Após a digestão, adicionaram-se $5 \mathrm{~mL}$ de $\mathrm{H}_{3} \mathrm{BO}_{3}$ a $1 \%$.

Tendo em vista os diferentes esquemas propostos por vários autores para fracionamento de metais pesados em solos, neste trabalho adotou-se um esquema baseado nos métodos de Tessier et al. (1979) 
e Shuman (1985), em função das características dos solos da área em estudo, desenvolvidos sobre rochas calcárias e com presença significativa de óxidos de Fe e matéria orgânica. O método adotado considerou as seguintes frações: (a) solúvel, (b) trocável, (c) ligado a carbonatos, (d) ligado a óxidos amorfos de Fe e Mn, (e) ligado a óxidos de Fe cristalinos, (f) ligado à matéria orgânica; e (g) residual (Quadro 1).

A determinação dos teores de $\mathrm{Zn}$ nos diferentes extratos foi realizada em espectrofotômetro de absorção atômica com chama de ar/acetileno, comprimento de onda de $248,3 \mathrm{~nm}$, fenda de $0,5 \mathrm{~nm}$ e corrente da lâmpada de 5,0 mA.

Para avaliar estatisticamente padrões distintos para os teores médios de Zn na camada superficial (0-20 cm) dos solos, foram consideradas análises de variância para os seguintes contrastes:

C1 - Perfis a montante versus perfis a jusante.

C2 - Perfis a montante + perfis a jusante versus área mineralizada não explorada + mineralizada em exploração.

C3 - Perfis a jusante versus área mineralizada não explorada + mineralizada em exploração.

C4 - Perfis a montante versus área mineralizada não explorada + mineralizada em exploração.

C5 - Perfis da área mineralizada não explorada versus área mineralizada em exploração.

\section{RESULTADOS E DISCUSSÃO}

Para simplificar a discussão sobre o processo da distribuição de $\mathrm{Zn}$ nas áreas amostradas, a interpretação da caracterização físico-química da análise granulométrica e da extração seqüencial limitou-se à camada de 0 a $20 \mathrm{~cm}$ de profundidade para cada perfil. Para isso, foi considerada a média ponderada dos teores obtidos nas profundidades de: 0-2, 2-5, 5-10 e 10-20 cm. Tal procedimento decorreu da observação de que a camada de $0-20 \mathrm{~cm}$ praticamente encerrava a mesma informação verificada nessas camadas isoladas. Além disso, essa é a camada normalmente utilizada em pesquisas para fins agrícolas e ambientais.

De modo geral, os solos situados fora da área mineralizada, os Latossolos (perfis 6, 8 e 10), o Neossolo Flúvico (7) e o Argissolo (perfil 9) apresentaram os maiores teores de argila (Quadro 2), com destaque para o Latossolo a montante (perfil 10), que apresentou classe textural muito argilosa. Os Cambissolos (perfis 3 e 5) localizados sobre a área mineralizada apresentaram textura mais arenosa (até cascalhenta), predominando em quase todas as camadas a textura franco-arenosa. Os Cambissolos (perfis 2 e 4) sobre a área mineralizada, o Neossolo Litólico (perfil 1) e o Cambissolo (perfil 11) próximo da área mineralizada, a montante do empreendimento, apresentaram textura intermediária em relação aos demais. Provavelmente, estes resultados podem ser creditados à localização na paisagem e ao menor estádio de desenvolvimento dos solos na escarpa, que corresponde à zona mineralizada (Figura 1).

Os solos apresentaram pH em $\mathrm{H}_{2} \mathrm{O}$ acima de 6 (Quadro 3) com exceção do Latossolo a montante (perfil 10). É importante destacar que os solos 3, 4, 5, 8,9 e 11 apresentam valores de $\mathrm{pH}$ maior que 7 . O pH é uma característica do solo importante na disponibilidade dos metais, já que controla a precipitação, a dissolução de carbonatos e hidróxidos, além da hidrólise de vários compostos orgânicos. Essa tendência de $\mathrm{pH}$ neutro/alcalino deve-se ao fato de esses solos serem influenciados pela rocha hospedeira da mineralização, os dolomitos.

\section{Quadro 1. Esquema de extração seqüencial adotado}

\begin{tabular}{|c|c|}
\hline Fração & Extrator \\
\hline Solúvel & Água deionizada; $2 \mathrm{~g}$ de solo e $20 \mathrm{~mL}$ de água; 30 min de agitação. \\
\hline Trocável & $\mathrm{Mg}\left(\mathrm{NO}_{3}\right)_{2} 1 \mathrm{~mol} \mathrm{~L}{ }^{-1}, \mathrm{pH} 7 ; 2 \mathrm{~g}$ de solo e $20 \mathrm{~mL}$ de solução; $1 \mathrm{~h}$ de agitação. \\
\hline Ligado a carbonatos & $\mathrm{NH}_{4} \mathrm{OAc} 1 \mathrm{~mol} \mathrm{~L}{ }^{-1}, \mathrm{pH} 5 ; 2 \mathrm{~g}$ de solo e $20 \mathrm{~mL}$ de solução; $5 \mathrm{~h}$ de agitação. \\
\hline $\begin{array}{l}\text { Ligado a óxidos } \\
\text { amorfos de Fe e Mn }\end{array}$ & $\begin{array}{l}\text { Oxalato de amônio } 0,2 \text { mol } \mathrm{L}^{-1} \text { e ácido oxálico } 0,2 \mathrm{~mol} \mathrm{~L}^{-1}, \mathrm{pH} 3 ; 2 \mathrm{~g} \text { de solo e } \\
20 \mathrm{~mL} \text { de solução; } 2 \mathrm{~h} \text { de agitação no escuro. }\end{array}$ \\
\hline $\begin{array}{l}\text { Ligado aos óxidos de } \\
\text { Fe cristalino }\end{array}$ & $\begin{array}{l}\left(\mathrm{NH}_{4}\right)_{2} \mathrm{C}_{2} \mathrm{O}_{4} \mathrm{H}_{2} \mathrm{O} 0,2 \mathrm{~mol} \mathrm{~L}^{-1} \mathrm{e} \mathrm{H}_{2} \mathrm{C}_{2} \mathrm{O}_{4} 0,2 \mathrm{~mol} \mathrm{~L}^{-1}, \mathrm{pH} 3 \text {, com ácido ascórbico } \\
0,1 \mathrm{~mol} \mathrm{~L} \mathrm{~L}^{-1} ; 2 \mathrm{~g} \text { de solo e } 20 \mathrm{~mL} \text { de solução; banho-maria por } 30 \text { min a } 100^{\circ} \mathrm{C} \text {; } \\
\text { agitação ocasional. }\end{array}$ \\
\hline Ligado à MO & $\begin{array}{l}\mathrm{NaOCl} 0,7 \mathrm{~mol} \mathrm{~L}^{-1} \text {, pH } 8,5 ; 2 \mathrm{~g} \text { de solo e } 10 \mathrm{~mL} \text { de solução; banho-maria por } \\
30 \mathrm{~min} \text { a } 100^{\circ} \mathrm{C} \text {; agitação ocasional, com repetição do processo. }\end{array}$ \\
\hline Residual & Residual $=$ Total $-\sum$ (frações anteriores) \\
\hline
\end{tabular}


Quadro 2. Análise granulométrica dos perfis de solos coletados

\begin{tabular}{|c|c|c|c|c|c|}
\hline \multirow{2}{*}{ Perfil } & \multicolumn{2}{|c|}{ Areia } & \multirow{2}{*}{ Silte $^{(1)}$} & \multirow{2}{*}{ Argila $^{(1)}$} & \multirow{2}{*}{ Classe } \\
\hline & Grossa & Fina & & & \\
\hline & \multicolumn{4}{|c|}{ dag $\mathrm{kg}^{-1}$} & \\
\hline \multicolumn{6}{|c|}{ Área mineralizada não explorada } \\
\hline 1 & 50 & 5 & 23 & 22 & Franco-Argilo-Arenosa \\
\hline 2 & 43 & 6 & 27 & 24 & Franco-Argilo-Arenosa \\
\hline 3 & 54 & 7 & 27 & 13 & Franco-Arenosa \\
\hline \multicolumn{6}{|c|}{ Área mineralizada em exploração } \\
\hline 4 & 13 & 8 & 53 & 27 & Franco-Argilo-Siltosa \\
\hline 5 & 42 & 16 & 33 & 10 & Franco-Arenosa \\
\hline \multicolumn{6}{|c|}{ Área a jusante do empreendimento } \\
\hline 6 & 11 & 8 & 28 & 53 & Argila \\
\hline 7 & 1 & 12 & 50 & 37 & Franco-Argilo-Siltosa \\
\hline 8 & 15 & 8 & 41 & 37 & Franco-Argilosa \\
\hline \multicolumn{6}{|c|}{ Área a montante do empreendimento } \\
\hline 9 & 18 & 12 & 27 & 43 & Franco-Argilosa \\
\hline 10 & 8 & 3 & 20 & 68 & Muito-Argilosa \\
\hline 11 & 25 & 7 & 41 & 28 & Franco-Argilosa \\
\hline
\end{tabular}

(1) Método da pipeta, Embrapa (1979).

Quadro 3. Caracterização química dos solos (médias nas camadas de 0-20 cm)

\begin{tabular}{|c|c|c|c|c|c|c|c|c|}
\hline \multirow{2}{*}{ Perfil } & \multicolumn{2}{|c|}{$\mathbf{p} \mathbf{H}^{(1)}$} & \multirow{2}{*}{$\mathbf{P}^{(2)}$} & \multirow{2}{*}{$\mathbf{S}^{(3)}$} & \multirow{2}{*}{$\mathrm{Al}^{(4)}$} & \multirow{2}{*}{$\mathrm{H}+\mathrm{Al}^{(5)}$} & \multirow{2}{*}{$\mathrm{T}^{(6)}$} & \multirow{2}{*}{$\mathrm{CO}^{(7)}$} \\
\hline & $\mathrm{H}_{2} \mathrm{O}$ & $\mathrm{KCl}$ & & & & & & \\
\hline & & & $\mathrm{mg} \mathrm{dm}^{-3}$ & 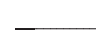 & $-\mathrm{c}$ & $\mathrm{dm}^{-3}$ & - & dag $\mathrm{kg}^{-1}$ \\
\hline 1 & 6,38 & 5,38 & 5,65 & 4,58 & 0,01 & 3,37 & 7,95 & 2,43 \\
\hline 2 & 6,25 & 5,51 & 4,73 & 2,76 & 0,01 & 2,87 & 5,64 & 3,51 \\
\hline 3 & 7,05 & 6,44 & 19,78 & 7,60 & 0,03 & 1,68 & 9,28 & 3,57 \\
\hline 4 & 7,48 & 6,90 & 13,99 & 11,44 & 0,02 & 0,31 & 11,78 & 4,44 \\
\hline 5 & 7,77 & 7,32 & 8,57 & 4,82 & 0,00 & 0,00 & 4,82 & 1,80 \\
\hline 6 & 6,38 & 5,41 & 1,29 & 9,20 & 0,01 & 3,57 & 13,08 & 2,64 \\
\hline 7 & 6,95 & 6,28 & 9,34 & 7,49 & 0,00 & 1,03 & 8,52 & 2,56 \\
\hline 8 & 7,84 & 7,21 & 29,43 & 9,91 & 0,00 & 0,00 & 9,91 & 1,97 \\
\hline 9 & 7,86 & 7,09 & 1,65 & 6,87 & 0,01 & 0,03 & 6,89 & 1,48 \\
\hline 10 & 5,71 & 4,73 & 1,86 & 4,39 & 0,02 & 5,08 & 9,47 & 3,06 \\
\hline 11 & 7,31 & 7,27 & 36,99 & 11,20 & 0,02 & 0,83 & 12,03 & 3,20 \\
\hline
\end{tabular}

${ }^{(1)}$ Relação solo:água (1:2,5). ${ }^{(2)}$ Extrator Mehlich-1 (Alvarez V., 1985). ${ }^{(3)}$ Soma de bases: $\mathrm{Ca}^{2+}+\mathrm{Mg}^{2+}+\mathrm{K}^{+}+\mathrm{Na}^{+}$. ${ }^{(4)} \mathrm{Alumínio}$ trocável, extrator $\mathrm{KCl} 1 \mathrm{~mol} \mathrm{~L}^{-1}$, Embrapa (1999). ${ }^{(5)}$ Extrator $\mathrm{Ca}\left(\mathrm{CH}_{3} \mathrm{COO}\right)_{2} 1 \mathrm{~mol} \mathrm{~L}^{-1} \mathrm{pH} 7(\mathrm{Embrapa}, 1999) .{ }^{(6)} \mathrm{T}=\mathrm{S}+\mathrm{H}+\mathrm{Al} \mathrm{e}$ ${ }^{(7)}$ Walkley-Black (Embrapa, 1999).

Os altos valores de $\mathrm{pH}$ em $\mathrm{KCl}$, porém menores que o $\mathrm{pH}$ em $\mathrm{H}_{2} \mathrm{O}$, em conjunto com os valores de capacidade de troca catiônica relativamente altos (Quadro 3), indicam predominância de cargas negativas nas argilas do solo. Altos valores de $\mathrm{pH}$ e CTC podem ser relacionados à menor mobilidade de metais pesados em solos (Pickering, 1981).

Os teores de C orgânico, de modo geral, são elevados e decrescem com a profundidade no perfil do solo (Quadro 3). A matéria orgânica do solo é responsável pela quelatação e complexação de metais pesados, por meio de grupos carboxílicos e fenólicos presentes em substâncias húmicas (Stevenson, 1982). Assim, espera-se que a matéria orgânica influencie na dinâmica dos metais pesados nas camadas superiores. Os altos valores de matéria orgânica na parte superficial especialmente daqueles solos sobre a área mineralizada indicam que o provável excesso de $\mathrm{Zn}$ nesses solos não inibiu o desenvolvimento da vegetação ao longo do processo de evolução dos solos. Além disso, 
o Zn pode formar complexos húmicos estáveis, com degradação limitada pelo desbalanço químico, o que favorece o acúmulo de matéria orgânica nos solos.

Verifica-se que, de modo geral, os teores de Zn são elevados na área como um todo (Quadro 4), e os perfis localizados sobre a área mineralizada apresentam teores muito superiores em relação aos perfis localizados à montante e a jusante. Esta observação geral é válida para todos extratores utilizados.

É evidente, ainda, um padrão decrescente dos teores de $\mathrm{Zn}$ em profundidade principalmente nos perfis localizados fora da área mineralizada (Figura 2). Para os perfis de solo sobre a área em exploração, também há um decréscimo em profundidade, particularmente para as formas mais lábeis (solúvel e trocável) e formas associadas aos óxidos de Fe e matéria orgânica. Por outro lado, na área mineralizada não explorada, revela-se um padrão diferente da distribuição do Zn nos perfís. Embora ainda ocorra alguma concentração na superfície notadamente nas formas mais lábeis, o padrão de distribuição é mais uniforme ou chega a se inverter, com aumento dos teores em profundidade para as formas mais estáveis (total e associadas a óxidos cristalinos), notadamente para o perfil 2. Supõe-se que estes padrões de distribuição dos metais permitem distinguir a contribuição litogênica da contaminação natural ou antropogênica de solos adjacentes às áreas mineralizadas. A distinção entre contaminação natural e antropogênica pressupõe padrões distintos de distribuição dos metais, em profundidade e em formas químicas, entre solos localizados a montante e a jusante da área minerada.

Observa-se que os teores de Zn nas várias frações, bem como o conteúdo total deste elemento, obtido pelo ataque triácido $\left(\mathrm{HF}-\mathrm{HNO}_{3}-\mathrm{HCl}\right)$, variaram amplamente entre solos, considerando-se os valores das médias ponderadas na camada de 0 a $20 \mathrm{~cm}$ (Quadro 4). Os

Quadro 4. Médias ponderadas dos teores de Zn obtidos por extração seqüencial e ataque total na camada superficial $(0-20 \mathrm{~cm})$ dos solos

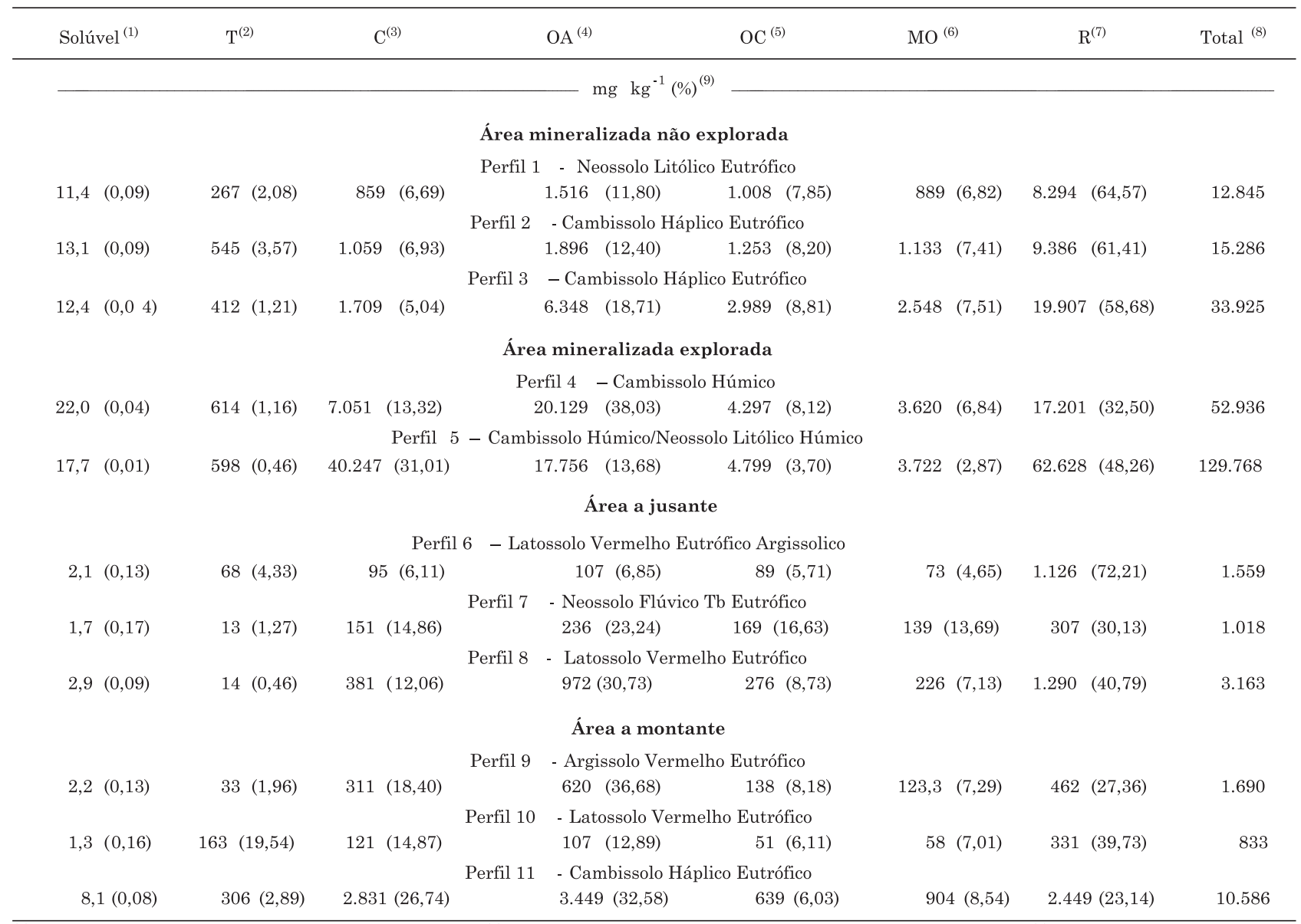

(1) Extraído com água (Miller \& Mcfee, 1983). ${ }^{(2)}$ Trocável: extraído com $\mathrm{Mg}\left(\mathrm{NO}_{3}\right)_{2}$ (Shuman, 1985). ${ }^{(3)}$ Associado a carbonatos: extraído com acetato de amônia (Shuman, 1985). ${ }^{(4)}$ Associado a óxidos amorfos: extraído com oxalato de amônio (Shuman, 1985).

${ }^{(5)}$ Associado a óxidos cristalinos: extraído com oxalato de amônio + ácido ascórbico (Shuman, 1985). ${ }^{(6)}$ Associado a matéria orgânica: extraído com hipoclorito de sódio (Shuman, 1985). ${ }^{(7)}$ Residual: total menos somatório das frações. ${ }^{(8)}$ Total: extraído com $\mathrm{HF}_{-} \mathrm{HNO}_{3}$-HCl. ${ }^{(9)}$ Valores entre parênteses referem-se às percentagens em relação ao total. 
Área Mineralizada Intocada

(a)

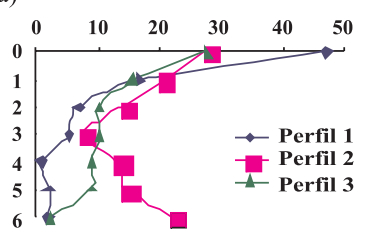

(b)

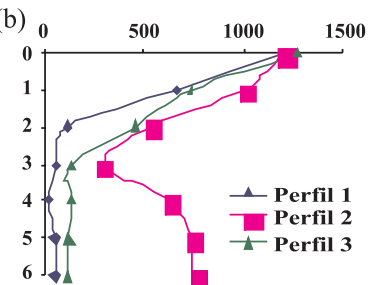

(c)

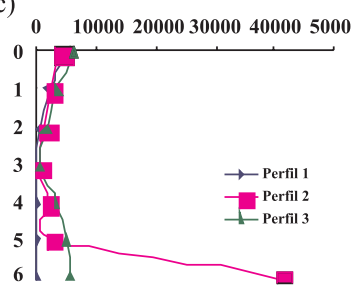

(d)

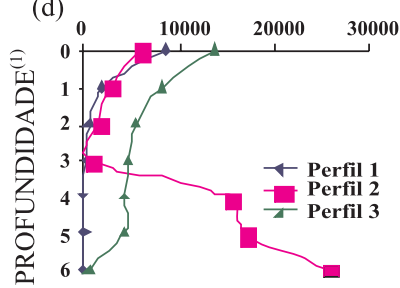

(e) $\begin{array}{llll}0 & 5000 & 10000 & 15000\end{array}$

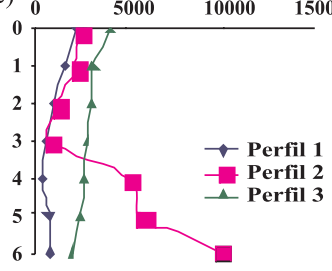

(f)

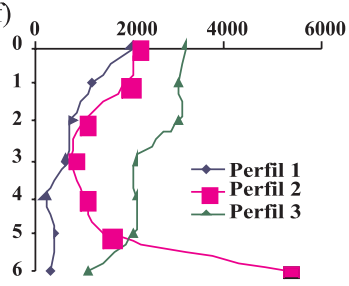

(g)

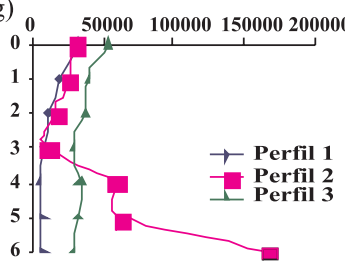

Área Minerada

Área Não Mineralizada a Jusante Área Não Mineralizada a Montante CONCENTRAÇÃO, $\mathrm{mg} \mathrm{kg}^{-1}$
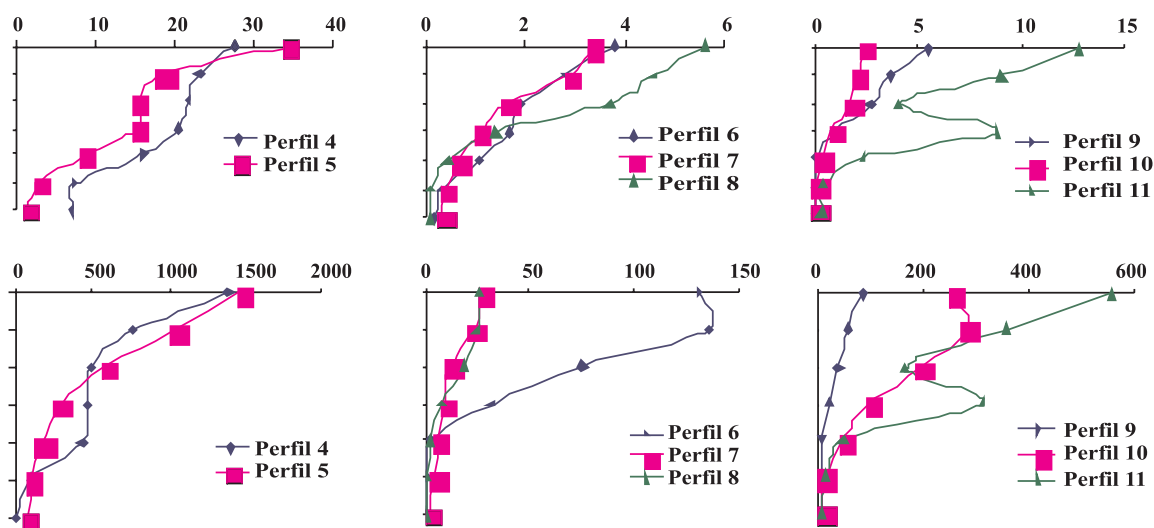

$0 \quad 1000020000300004000050000$
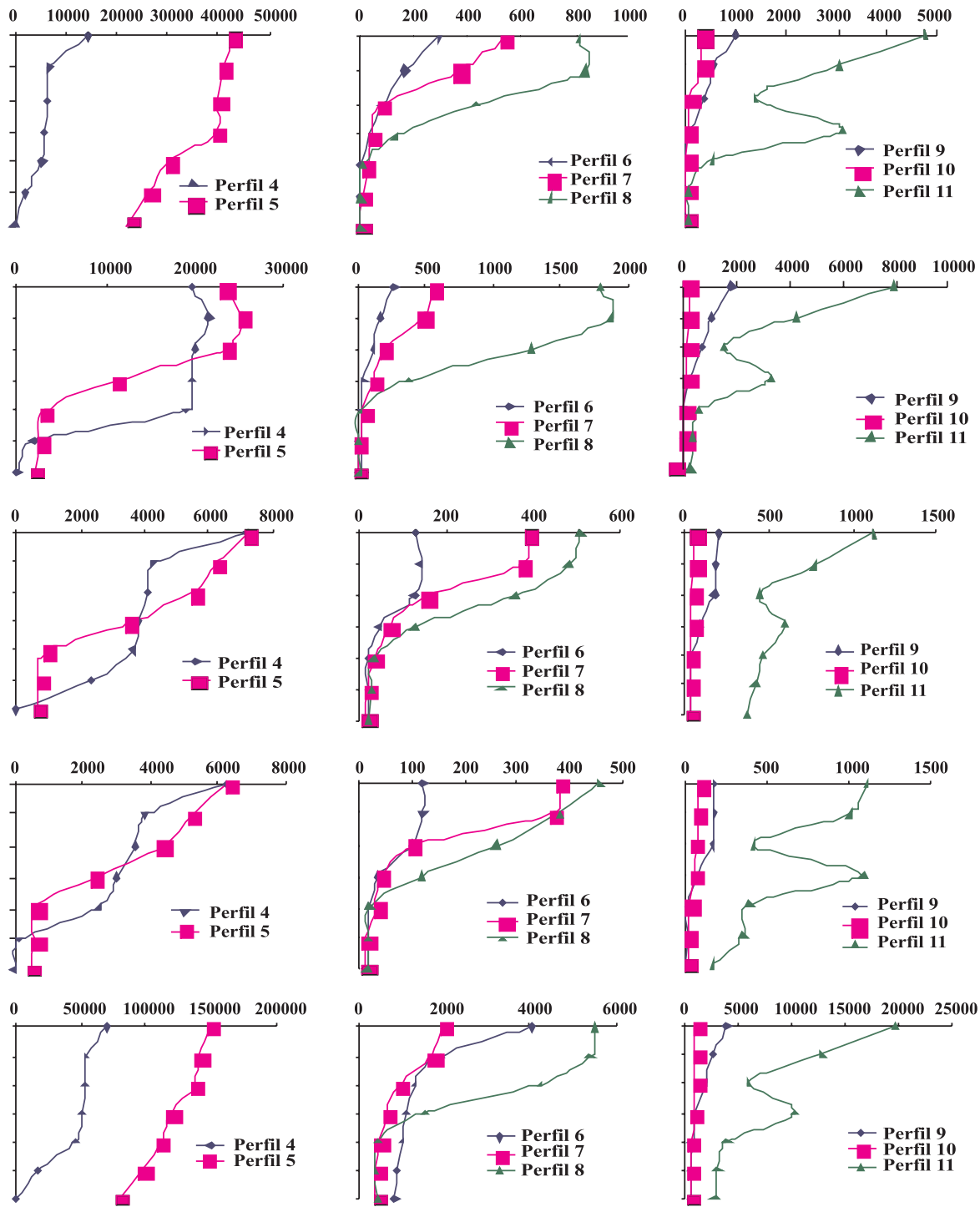

(1) As profundidades $0,1,2,3,4,5$ e 6 correspondem a 0-2, 2-5, 5-10, 10-20, 20-50,50-100 e 100-150 cm, respectivamente.

Figura 2. Teor de Zn em função da profundidade nos perfis de solos das áreas em estudo. (a) forma solúvel; (b) forma trocável; (c) forma associada a carbonato; (d) forma associada aos óxidos amorfos; (e) forma associada aos óxidos cristalinos; (f) forma associada à matéria orgânica; (g) total. 
maiores teores de $\mathrm{Zn}$ foram obtidos para os Cambissolos sobre a área minerada, com destaque para o perfil 5. Por outro lado, os menores teores foram obtidos para os Latossolos a montante e a jusante (perfis 6 e 10, respectivamente) e para o Neossolo Flúvico (a jusante).

Os teores de Zn nos perfis localizados a montante são semelhantes ou superam aqueles localizados a jusante. Especialmente o perfil 11, a montante, apresentou valores bastante elevados. Em conseqüência, as médias dos teores das áreas a montante são superiores às de jusante (Quadro 4). Não obstante, estas diferenças não se revelaram significativas pelo contraste $\mathrm{C} 1$ que compara as médias de montante e jusante (Quadro 5), ou seja, não há diferenças significativas entre os teores médios de $\mathrm{Zn}$ das áreas a montante e a jusante para todas as formas químicas avaliadas. Por outro lado, os teores médios de $\mathrm{Zn}$ em todas as frações da extração seqüencial foram superiores nos perfis das áreas mineralizadas (não explorada e em exploração) em relação às áreas não mineralizadas a montante e jusante (contrastes C2, C3 e C4). Exceção feita para o Zn extraído com acetato de amônio (associado a carbonatos), no qual não há diferença a $5 \%$ (contrastes C3 e C4). Observa-se, ainda, que os teores médios de Zn nos perfis da área mineralizada em exploração foram superiores àqueles encontrados na área mineralizada não explorada (contraste C5), a 1 e 5 \%.

Os teores totais de $\mathrm{Zn}$ encontrados naturalmente em solos variam na faixa de 10 a $300 \mathrm{mg} \mathrm{kg}^{-1}$ (Alloway, 1993). Portanto, os teores totais encontrados neste trabalho confirmam a anomalia geológica presente na área. Em muitos perfis, mesmo considerando apenas os teores das formas solúvel e trocável mais lábeis, obtêm-se valores superiores aos dos teores totais reportados por Alloway (1993).

Conforme observado anteriormente (Quadro 4), as áreas a jusante apresentaram os menores teores médios de Zn. Estas áreas apresentam solos mais intemperizados, com textura mais argilosa e em cota inferior, em relação às áreas mineralizadas (não explorada e em exploração) (Figura 2). Além disso, os valores médios não diferem estatisticamente em relação às áreas da montante. Portanto, os resultados obtidos decorrem do fato de ser esta uma região anômala, onde existe uma faixa mineralizada com um potencial de contaminação natural, mas não caracterizam a dispersão do Zn nas áreas adjacentes como fruto de atividade antrópica.

Verifica-se que, de modo geral, o Zn é encontrado predominantemente associado às formas residual, ligadas a óxidos amorfos, carbonatos e óxidos cristalinos em ordem decrescente (Quadro 4). A soma dos teores das formas mais lábeis (solúvel e trocável), de modo geral, contribui pouco (menos de $5 \%$ ), relativamente ao conteúdo total de Zn nas camadas superficiais dos solos. Esses resultados estão de acordo com os apresentados por Shuman (1985), indicando baixa disponibilidade de $\mathrm{Zn}$ devido à sua ligação preferencial por formas altamente estáveis. Não obstante, os valores destas formas mais lábeis representam parte substancial da CTC total do solo.

As maiores contribuições na retenção de $\mathrm{Zn}$ pelos óxidos amorfos, em relação aos cristalinos, podem ser explicadas pelos teores de matéria orgânica elevados,

Quadro 5. Valores de quadrado médio da análise de variância para zinco de acordo com as extrações realizadas

\begin{tabular}{|c|c|c|c|c|c|}
\hline$F V^{(1)}$ & $G L^{(2)}$ & $S^{(3)}$ & $T^{(4)}$ & $\mathbf{C}^{(5)}$ & $\mathrm{OA}^{(6)}$ \\
\hline $\mathrm{C} 1$ & 1 & $4,08^{\mathrm{ns}}$ & $27.600^{\mathrm{ns}}$ & $1.157 .239^{\mathrm{ns}}$ & $1.364 .631^{\mathrm{ns}}$ \\
\hline $\mathrm{C} 2$ & 1 & $508,56^{* *}$ & $498.915^{* *}$ & $416.332 .500^{*}$ & $311.064 .200^{* *}$ \\
\hline $\mathrm{C} 3$ & 1 & $383,37^{* *}$ & $452.445^{* *}$ & $298.635 .300^{\mathrm{ns}}$ & $227.255 .800 * *$ \\
\hline $\mathrm{C} 4$ & 1 & $297,44^{* *}$ & $231.175^{* *}$ & $257.246 .200^{\mathrm{ns}}$ & $188.406 .200^{* *}$ \\
\hline C5 & 1 & $84,75^{* *}$ & $58.836^{*}$ & $755.338 .800^{*}$ & $369.234 .500^{* *}$ \\
\hline Resíduo & 8 & 4,73 & 9.761 & 69.503 .390 & 3.021 .192 \\
\hline \multirow[t]{2}{*}{$\mathrm{CV}^{(7)}(\%)$} & & 22,78 & 32,6 & 127,5 & 28,9 \\
\hline & & $\mathrm{OC}^{(8)}$ & MO $^{(9)}$ & Residual & Tota 1 \\
\hline $\mathrm{C} 1$ & 1 & $14.330,6^{\mathrm{ns}}$ & $70.062^{\mathrm{ns}}$ & $45.044^{\mathrm{ns}}$ & $9.052 .299^{\mathrm{ns}}$ \\
\hline $\mathrm{C} 2$ & 1 & $25.618 .370^{* *}$ & $16.474 .050^{* *}$ & $1.909 .319 .000^{* *}$ & $8.388 .027 .000^{* *}$ \\
\hline $\mathrm{C} 3$ & 1 & $17.654 .950 * *$ & $12.018 .950 * *$ & $1.281 .638 .000^{*}$ & $5.854 .831 .000^{* *}$ \\
\hline $\mathrm{C} 4$ & 1 & $16.512 .430^{* *}$ & $9.993 .161^{* *}$ & $1.264 .151 .000^{*}$ & $5.335 .238 .000^{* *}$ \\
\hline C5 & 1 & $11.743 .820^{* *}$ & $6.920 .685^{* *}$ & $1.124 .949 .000^{*}$ & $7.490 .655 .000^{* *}$ \\
\hline Resíduo & 8 & 334.799 & 257.975 & 139.674 .100 & 409.797.100 \\
\hline CV (\%) & & 34,3 & 35,6 & 86,9 & 68,4 \\
\hline
\end{tabular}

(1) Fontes de Variação. ${ }^{(2)}$ Graus de Liberdade. ${ }^{(3)}$ Solúvel. ${ }^{(4)}$ Trocável. ${ }^{(5)}$ Associado a carbonatos. ${ }^{\left({ }^{()}\right.}$Associado a óxidos amorfos.

(7) Coeficiente de Variação. ${ }^{\left({ }^{(7)}\right.}$ Associado a óxidos cristalinos. ${ }^{(9)}$ Associado a matéria orgânica. 
pela maior superfície de adsorção dos compostos amorfos e altos valores de $\mathrm{pH}$. A retenção de metais pela superfície de óxidos é inversamente dependente do grau de cristalinidade. Devido às cargas variáveis dos óxidos, essa retenção é dependente do pH (Okazaki et al., 1986).

Apesar da pequena contribuição, em termos percentuais, das formas mais lábeis, em valores absolutos o teor de Zn é alto. Incluindo a fração ligada à matéria orgânica nas formas lábeis, esta contribuição chega a quase $16 \%$ em relação ao conteúdo total. Neste caso, deve-se destacar que mais de $50 \%$ da soma dos teores das formas lábeis diz respeito à fração ligada à matéria orgânica. Shuman (1986) e Sims (1986) têm mostrado o importante papel da matéria orgânica na complexação de Zn em solos com valores de $\mathrm{pH}$ elevado.

A elevação do $\mathrm{pH}$ favorece as reações de hidrólise envolvendo a formação de espécies monoméricas, que, por sua vez, são responsáveis pelo aumento da adsorção específica. Além disso, altos valores de $\mathrm{pH}$ favorecem a ionização de grupos carboxílicos e fenólicos presentes em substâncias húmicas (Stevenson, 1982). Portanto, pode-se supor que os teores relativamente elevados nas frações solúvel e trocável se devam ao acúmulo de material orgânico nas camadas superficiais que se decompõe ou é solubilizado em função dos altos valores de $\mathrm{pH}$ natural do ambiente. Assim, o Zn associado à fração mais lábil da matéria orgânica torna-se disponível, passando a fazer parte das formas solúvel e trocável. Tais mecanismos podem produzir uma contaminação natural, notadamente na superfície dos solos, pela reciclagem biológica. O material humificado, por sua vez, favorece a complexação e a manutenção dos teores relativamente elevados das formas ligadas à matéria orgânica.

No perfil 10, verifica-se uma contribuição significativa de Zn na forma trocável, em média $19,54 \%$ nos primeiros $20 \mathrm{~cm}$ (Quadro 4). Vale lembrar que se trata de um Latossolo VermelhoAmarelo eutrófico, a montante da área mineralizada (Figura 2). A localização desse solo fora da área mineralizada é sugerida, também, pelos teores total e residual relativamente baixos nesse solo em relação aos demais, notadamente nas camadas mais profundas (Figura 3). O perfil característico de diminuição da participação das formas mais lábeis (solúvel e trocável) e aumento do residual em relação ao total, com decréscimo dos teores em profundidade, sugere contaminação superficial do solo 10. A posição deste solo na paisagem, a montante da área minerada (Figura 2), e o fato dessa contaminação não se restringir apenas aos primeiros centímetros do solo indicam que ela não é recente e, por conseguinte, não pode ser creditada exclusivamente à ação antrópica.

Outro fator que pode estar contribuindo para a elevação do teor de $\mathrm{Zn}$ trocável no perfil 10 é o $\mathrm{pH}$. Este é o único solo a apresentar $\mathrm{pH}$ abaixo de 6,0 nas camadas de 0 a $20 \mathrm{~cm}$ (Quadro 3). Segundo André et al. (2003), a acidificação gradual do solo acarreta mudanças na distribuição dos metais em diferentes frações do solo. De fato, Xiang et al. (1995) já haviam observado que a forma de $\mathrm{Zn}$ trocável torna-se representativa em solos ácidos. Por outro lado, Sims \& Patrick (1978) também observaram decréscimos na fração trocável quando o $\mathrm{pH}$ é aumentado. Segundo Zhang et al. (1997), a elevação do $\mathrm{pH}$ do solo proporciona a precipitação de cátions metálicos sobre óxidos de $\mathrm{Fe}$ e $\mathrm{Mn}$ (amorfo e cristalino), ocasionando decréscimos nas formas trocável e ligada à matéria orgânica.

Um fato que merece destaque é a significativa elevação dos teores de Zn na camada de 10 a $20 \mathrm{~cm}$ do perfil 11 (Figura 3). Esse perfil apresenta um horizonte A enterrado na profundidade de 18 a $23 \mathrm{~cm}$. Considerando que esse horizonte apresenta uma contribuição significativa no aumento do C orgânico nessa profundidade e que alguns compostos orgânicos podem complexar $\mathrm{Zn}$ em solos com valores de $\mathrm{pH}$ elevado, supõe-se que o aumento de Zn nessa camada foi causado por bioacumulação. Verifica-se, ainda, que esse acúmulo de Zn na camada superficial não se limita às formas mais lábeis, com uma concentração bastante evidente da fração associada à matéria orgânica no horizonte A enterrado. Esse fato somado à localização do perfil a montante da área mineralizada sugerem que pode haver uma contaminação natural causada pela ciclagem biológica, dado que o horizonte enterrado possivelmente formou-se em épocas pretéritas, não compatíveis com a ação antrópica atual.

Foram encontrados teores significativos de $\mathrm{Zn}$ ligado à fração carbonato em Latossolos e no Argissolo avaliados neste estudo. Entretanto, não se espera encontrar mais essa fração nessas classes de solo, uma vez que, sob o clima atual, o intemperismo já teria eliminado, por lixiviação, os carbonatos destes perfis. $\mathrm{O}$ extrator utilizado para $\mathrm{Zn}$ ligado a carbonatos foi o acetato de amônio (Quadro 5), que, na ausência da fração carbonato, deve ter atacado outras frações subseqüentes no esquema de fracionamento. Sabe-se que, na prática, a seletividade de um extrator não é completa. Assim, acredita-se que, no caso específico destes solos, tenha ocorrido a extração de parte do Zn ligado a óxidos amorfos, possivelmente por complexação pelo acetato.

\section{CONCLUSÕES}

1. De modo geral, os teores de Zn em perfis de solos adjacentes à área de mineração no município de Vazante-MG foram muito altos. Mesmo considerando apenas as formas mais lábeis, obtêm-se valores superiores aos teores totais normalmente encontrados em solos.

2. Há um padrão decrescente dos teores em profundidade, comum nos perfis de solos localizados a montante e a jusante da área mineralizada. Por outro 
lado, verifica-se um aumento dos teores de Zn em profundidade para um Cambissolo sobre a área mineralizada. Esses padrões sugerem a possibilidade de distinguir anomalias litogênicas de áreas contaminadas por dispersão natural ou antrópica do $\mathrm{Zn}$, a partir de sua distribuição nos perfis.

3. Os teores médios de Zn nas camadas superficiais dos solos sobre as áreas mineralizadas foram significativamente superiores em relação àqueles localizados a montante e jusante para todas as formas de Zn avaliadas. Não se verificaram diferenças significativas entre os teores médios de Zn das áreas a montante e a jusante da mineração, de modo que não se pode presumir contaminação por ação antrópica.

4. De modo geral, o Zn encontra-se principalmente em formas pouco lábeis, predominantemente nas frações residual e associada a óxidos amorfos, seguidas das formas associadas a carbonatos e óxidos cristalinos.

5. O acetato de amônio extraiu quantidades significativas de Zn em Latossolos e Argissolo, sugerindo que o extrator não é específico das formas associadas a carbonatos.

\section{LITERATURA CITADA}

ALLOWAY, B.J. Heavy metals in soils. London, Black Academic, 1993. 339p.

AMARAL SOBRINHO, N.M.B.; VELOSO, A.C.X. \& OLIVEIRA, C. Solubilidade de metais pesados em solo tratado com resíduo siderúrgico. R. Bras. Ci. Solo, 21:9-16, 1997.

ANDRÉ, E.M.; CRUZ, M.C.P.; FERREIRA, M.E. \& PALMA, L.A.S. Frações de zinco em solo arenoso e suas relações com disponibilidade para Cynodon spp cv. Tifton-85. R. Bras. Ci. Solo, 27:451-459, 2003.

BASÍLIO, M.S.; FRIESE, K.; LENA, J.C.; NALINI JR, H.A. \& ROESER, H.M.P. Adsorção de as, $\mathrm{Cu}, \mathrm{Pb}$ e $\mathrm{Cr}$ na avaliação da capacidade de fixação de metais por resíduo de mineradoras de ferro. Quimica Nova, 28:822-828, 2005.

CAMARGO, O.A.; MONIZ, A.C.; JORGE, J.A. \& VALADARES, J.M.A.S. Métodos de análise química, mineralógica e física de solo. Campinas, Instituto Agronômico de Campinas, 1986. 94p. (Boletim Técnico, 106)

CANEPARI, S.; CARDARELLI, E.; GHIGHI, S. \& SCIMONELLI, L. Ultrasound and microwave-assisted extraction of metals from sediment: A comparison with the BCR procedure. Talanta, 66:1122-130, 2005.

CHAO, T. Selective dissolution of manganese oxides from soils and sediments with acidified hidroxilamine hydrochloride. Soil Sci. Soc. Am. Proc., 36:764-768, 1972.

CHLOPECKA, A.; BACON, J.R.; WILSON, M.J. \& KAY, J. Forms of cadmiun, lead and zinc in contaminated soils from Southwest Poland. J. Environ. Qual., 25:69-79, 1996.
EMPRESA BRASILEIRA DE PESQUISA AGROPECUÁRIA EMBRAPA. Serviço Nacional de Levantamento e Conservação de Solos. Manual de métodos de análises químicas de solo. Rio de Janeiro, 1979. 412p.

EMPRESA BRASILEIRA DE PESQUISA AGROPECUÁRIA EMBRAPA. Manual de análises químicas de solos, plantas e fertilizantes. Brasília, Embrapa Comunicação para Transferência de Tecnologia, 1999. 370p.

GLEYZES, C.; TELLIER, S. \& ASTRUC, M. Fractionation studies of trace elements in contaminated soils and sediments: A review of sequential extraction procedures. Trends Anal. Chem., 21:451-467, 2002.

GUEVARA-RIBA, A.; SAHUQUillo, A.; RUBIO, R. \& RAURET, G. Assessment of metal mobility in dredged harbour sediments from Barcelona, Spain. Sci. Total Environ., 321:241-255, 2004.

MILLER, W.P.; MARTENS, D.C. \& ZELAZNY, L.W. Effect of sequence in extraction of trace metals from soils. Soil Sci. Am. J., 50:598-601, 1986.

MONTEIRO, L.V.S. Contribuição à gênese das mineralizações de Zn na mina de Vazante, MG. São Paulo, Universidade de São Paulo, 1997. 159p. (Tese de Mestrado)

MOREIRA-NODERMANN, L.M. A geoquímica e o meio ambiente. Geochim. Bras., 1:89-107, 1987.

OKAZAKI, M.; TAKAMIDOH, K. \& YAMANE, I. Adsorption of heavy metal cations on hydrated oxides of iron and aluminum with different crystallinities. Soil Sci. Plant Nutr., 3:523-533, 1986.

PAZOS-CAPEÁNS, P.; BARCIELA-ALONSO, M.C.; BARMEJO-BARRERA, A. \& BARMEJO-BARRERA, P. Chromium available fractions in arousa sediments using a modified microwave BCR protocol based on microwave assisted extraction. Talanta, 65:678-685, 2005.

PEREIRA, J.C.; GUIMARÃES-SILVA, A.K.; NALINI JÚNIOR, H.A.; PACHECO-SILVA, E. \& LENA, J.C. Distribuição, fracionamento e mobilidade de elementos-traço em sedimentos superficiais. Química Nova, 30:1249-1255, 2007.

PICKERING, W.F. Selective chemical extraction of soil components in bound metal species. Crit. Rev. Anal. Chem., 11:233-266, 1981.

RIBEIRO-FILHO, M.R.; SIQUEIRA, J.O. \& SIMÃO, J.B.P. Fracionamento e biodisponibilidade de metais pesados em solo contaminado, incubado com materiais orgânicos e inorgânicos. R. Bras. Ci. Solo, 25:495-507, 2001.

RAURET, G. Extraction procedures for the determination of heavy metals in contaminated soils and sediments. Talanta, 46:449-455, 1998.

RIGOBELLO, A.E.; BRANQUINHO, J.A.; DANTAS, M.G.S.; OLIVEIRA, T.F. \& NIEVES FILHO, W. Mina de zinco de Vazante, Minas Gerais. In: DEPARTAMENTO NACIONAL. DE PRODUÇÃO MINERAL - DNPM. Principais dépósitos minerais do Brasil. 1988. v.2. 670p. 
SHUMAN, L.M. Effect of liming on the distribution of manganese, copper, iron, and zinc among soil fractions. Soil Sci. Soc. Am. J., 50:1236-1240, 1986.

SHUMAN, L.M. Fractionation method for soil microelements. Soil Sci., 140:11-22, 1985.

SIMS, J.T. Soil $\mathrm{pH}$ effects on the distribution and plant availability of manganese, copper, iron and zinc. Soil Sci. Soc. Am. J., 50:367-373, 1986.

SIMS, J.L. \& PATRICK, W.H. The distribution of micronutrients cations in soil under conditions of varying redox potential e pH. Soil Sci. Soc. Am. Proc., 42:258-262, 1978.
STEVEnSON, F.J. Humus chemistry. New York, John Wiley, 1982. 443p.

TESSIER, A.; CAMPBEL, P.G.C. \& BISSON, M. Sequential extraction procedure for the speciation of particulate trace metals. Anal. Chem., 51:844-850, 1979.

XIANG, H.F.; TANG, H.A. \& YING, Q.H. Transformation and distribution of zinc in acid, neutral and calcareous soils of China. Geoderma, 66:121-135, 1995.

ZHANG, M.; ALVA, A.K.; LI, Y.C. \& CALVERT, D.V. Chemical association of $\mathrm{Cu}, \mathrm{Zn}, \mathrm{Mn}$ and $\mathrm{PB}$ in selected Sandy citrus soils. Soil Sci., 1962:181-188, 1997. 